\title{
ANALISIS KOVARIANSI RANCANGAN PETAK TERBAGI PADA RANCANGAN ACAK KELOMPOK (RAK) DENGAN DATA HILANG
}

\author{
YULIANA.DEWI PURI ${ }^{1}$,NASRAH,S ${ }^{2}$ DAN ,NURTITI,S ${ }^{3}$
}

\begin{abstract}
Abstrak
Pada skripsi ini akan di kaji analisis kovariansi rancangan petak terbagi (split plot design) pada Rancangan Acak Kelompok (RAK) dengan satu data hilang. Analisis kovariansi pada rancangan petak terbagi dilakukan melalui dua analisis yaitu analisis petak utama dan analisis anak petak. Sebagai aplikasi selanjutnya diberikan studi kasus pada percobaan dengan satu data hilang. Dari hasil analisis rancangan petak terbagi pada Rancangan Acak Kelompok (RAK) dengan satu data hilang diperoleh nilai koefisien keragaman dari analisis variansi lebih kecil dibandingkan analisis kovariansi. Hal ini menunjukkan analisis variansi lebih baik dibandingkan analisis kovariansi pada rancangan petak terbagi (split plot design) pada Rancangan Acak Kelompok (RAK) dengan satu data hilang.
\end{abstract}

Kata kunci : analisis kovariansi, rancangan petak terbagi, variabel konkomitan, data hilang. ${ }^{1}$

\section{PENDAHULUAN}

Rancangan percobaan merupakan pengaturan pemberian perlakuan kepada unit - unit percobaan dengan maksud agar keragaman respon yang ditimbulkan oleh lingkungan dan keheterogenan percobaan yang digunakan dapat diminimalkan (Gaspersz, 1991).Dalam suatu percobaan, variabel $Y$ adalah suatu variabel respons yang terjadi akibat pengaruh suatu faktor atau beberapa faktor. Akan tetapi, dalam kenyataannya nilai variabel $Y$ bisa berubah-ubah karena adanya variabel $X$ yang tidak dapat dikendalikan sehingga tidak dapat diabaikan pada saat melakukan percobaan. Variabel $X$ yang bersifat demikian disebut variabel konkomitan (Sudjana,2002). Variabel konkomitan merupakan variabel lain yang muncul dalam suatu percobaan yang tidak dapat dikendalikan sehingga dapat mempengaruhi variabel respons yang sedang diamati dalam penelitian. Adanya variabel konkomitan dalam suatu percobaan akan mempengaruhi tingkat ketelitian hasil percobaan serta analisisnya. Dengan demikian, untuk melakukan analisis mengenai variabel respon $Y$ sebagai pengaruh faktor, maka yang harus dilakukan terlebih dahulu adalah memurnikan variabel respon $Y$ dari variabel konkomitan $X$. Hal ini dapat dilakukan dengan cara mengoreksi pengaruh $X$ terhadap variabel respon $Y$. Selanjutnya, lakukan analisis terhadap variabel respon $Y$ yang sudah dimurnikan untuk melihat pengaruh faktor yang diselidiki (Sudjana, 2002). Nilai $Y$ yang sudah dimurnikan tersebut dinamakan $Y$ terkoreksi. Analisis yang digunakan untuk mengontrol adanya variabel

1,2,3 Jurusan Matematika FMIPA Universitas Hasanuddin Makassar, Jl. Perintis Kemerdekaan Km.10 Makassar

E-mail: yulianadewiputri@yahoo.com 
konkomitan dalam suatu percobaan dinamakan analisis kovariansi.Analisis kovariansi merupakan kombinasi dari analisis variansi dengan analisis regresi.

Pada kasus percobaan pada rancangan petak terbagi (RPT) dapat terjadi data hilang. Sehingga diperlukan dugaan terhadap data hilang tersebut. Penentuan dugaan data hilang dapat dilakukan dengan menggunakan rumus baku. Setelah dugaan data hilang ditentukan, dilakukan analisis terhadap data hilang dengan menggunakan analisis kovariansi. Analisis kovariansi digunakan apabila terjadi respon yang diduga sebagai efek perlakuan yang diiringi oleh terjadinya variabel lain yang sifatnya berkorelasi dengan respon yang diamati. Analisis kovarians dapat meningkatkan ketepatan penelitian sehingga analisis kovarians memberikan hasil yang lebih baik dibandingkan dengan analisis varians.Para peneliti sebelumnya telah menggunakan analisis kovariansi pada berbagai rancangan percobaan seperti yang di lakukan oleh Auna (2010) dengan menggunakan analisis kovariansi pada Rancangan Bujur Sangkar Latin (RBSL) pada data hilang, Erlina (2011) menggunakan analisis kovariansi pada Rancangan Bujur Sangkar Hyper Graeco Latin, Ratna (1997) menggunakan analisis variansi percobaan petak terbagi. Penelitian tentang aplikasi rancangan petak terbagi yang dilakukanoleh Almimi (2005) pada bidang industry, Bradley (2009) melakukan penelitian tentang apa dan bagaimana proses penggunaan rancangan petak terbagi dengan menggunakan metode analisis variansi dan robust.

\section{TINJAUAN PUSTAKA}

\section{Rancangan Percobaan}

Suatu percobaan dilakukan untuk menguji sesuatu yang telah diketahui atau diduga kemudian dirumuskan dalam suatu penelitian ilmiah. Secara umum, tujuan diadakannya suatu percobaan adalah untuk memperoleh keterangan tentang bagaimana respon yang akan diberikan oleh suatu objek pada berbagai keadaan tertentu yang diperhatikan.Unsur-unsur utama rancangan percobaan adalah sebagai berikut:

1. Pengulangan (replication)

2. Pengacakan ( randomization)

3. Pengendalian lokal (local control)

\section{Rancangan Petak Terbagi}

Rancangan petak terbagi (split plot design) merupakan modifikasi percobaan faktorial seperti percobaan faktorial RAL atau RAK. Perbedaanya terletak pada penempatan perlakuan ke dalam satuan-satuan percobaan. Rancangan petak terbagi terdiri dari petak utama dan anak petak.Model statistik untuk percobaan yang terdiri dari dua faktor (A dan B) dengan menggunakan rancangan petak terbagi dalam RAK adalah sebagai berikut:

$$
\begin{gathered}
Y_{i j k}=\mu+K_{k}+\alpha_{i}+\beta_{j}+\delta_{i k}+(\alpha \beta)_{i j}+e_{i j k} \\
i=1, \ldots, a ; j=1, \ldots, b ; \quad k=1, \ldots, r(1)
\end{gathered}
$$

dimana :

$Y_{i j k}=$ Nilai pengamatan (respon) pada kelompok ke- $k$ yang memperoleh taraf ke- $i$ dari faktor A dan taraf ke- $j$ dari faktor $B$.

$\mu=$ Nilai rata-rata umum

$K_{k}=$ Pengaruh aditif dari kelompok ke- $k$

$\alpha_{i}=$ Pengaruh aditif dari taraf ke- $i$ faktor $A$

$\beta_{j}=$ Pengaruh aditif dari taraf ke- $j$ faktor $B$

$\delta_{i k}=$ Pengaruh galat yang muncul pada taraf ke $-i$ dari faktor $A$ dalam kelompok ke- $k$ dan biasa disebut galat petak utama (galat $a$ ) 
$(\alpha \beta)_{i j}=$ Pengaruh interaksi taraf ke- $i$ faktor $A$ dan taraf ke- $j$ faktor $B$

$e_{i j k}=$ Pengaruh galat pada kelompok ke- $k$ yang memperoleh taraf ke- $i$ faktor $A$ dan taraf ke- $j$ faktor $B$ dan biasa disebut sebagai galat anak petak (galat $b$ )

Tabel 1. Analisis Variansi pada Rancangan Petak Terbagi (RPT) dari dua faktor dalam RAK

\begin{tabular}{|c|c|c|c|}
\hline Sumber Keragaman & $D B$ & $J K$ & $K T$ \\
\hline $\begin{array}{l}\text { Petak Utama: } \\
\text { Kelompok } \\
\text { Faktor A } \\
\text { Galat } a \\
\end{array}$ & $\begin{array}{c}r-1 \\
a-1 \\
(a-1)(r-1) \\
\end{array}$ & $\begin{array}{c}J K K \\
J K A \\
J K G a \\
\end{array}$ & $\begin{array}{c}K T K \\
K T A \\
K T G a \\
\end{array}$ \\
\hline $\begin{array}{l}\text { Anak Petak: } \\
\text { Faktor B } \\
\text { Interaksi AB } \\
\text { Galat }\end{array}$ & $\begin{array}{c}b-1 \\
(a-1)(b-1) \\
a(r-1)(b-1)\end{array}$ & $\begin{array}{l}J K B \\
J K A B \\
J K G b\end{array}$ & $\begin{array}{c}K T B \\
K T A B \\
K T G b\end{array}$ \\
\hline Total & $a b r-1$ & $J K T$ & - \\
\hline
\end{tabular}

Sumber :Gasperz, 1991

\section{Data hilang dalam Rancangan Petak Terbagi}

Menurut (Gaspersz,1991) Jika ada sebuah data yang hilang dalam rancangan petak terbagi yang menggunakan rancangan dasar RAK , maka data tersebut dapat diperkirakan melalui rumus :

$Y=\frac{b R+r M-P}{(b-1)(r-1)}$

dimana :

$Y=$ Nilai dugaan terhadap data hilang

$b=$ Banyaknya taraf faktor yang di jadikan anak petak

$r=$ Banyaknya kelompok (ulangan)

$R=$ Total nilai pengamatan dari perlakuan yang mengandung data hilang

$M=$ Total nilai pengamatan dari petak utama yang mengandung data hilang

$P=$ Total nilai pengamatan dari taraf faktor dalam petak utama (taraf dari faktor yang di jadikan petak utama) yang mengandung data hilang.

\section{Analisis Kovariansi}

Analisis kovarians merupakan alat statistika untuk menyelesaikan masalah yang dijumpai dalam banyak bidang penelitian biologi. Suatu analisis data dengan cara menggabungkan analisis varians dan analisis regresi disebut dengan analisis kovariansi atau disingkat menjadi ANAKOVA (Schefler, 1987) .

\section{Analisis Kovariansi Pada Rancangan Petak Terbagi}

Model linier analisis kovarians dalam rancangan petak terbagi adalah sebagai berikut:

$Y_{i j k}=\mu+K_{k}+\alpha_{i}+\beta_{j}+\delta_{i k}+(\alpha \beta)_{i j}+\gamma\left(X_{i j k}-\bar{x}_{\ldots}\right)+e_{i j k}$

dimana : 
$Y_{i j k}=$ Nilai pengamatan (respon) pada kelompok ke- k yang memperoleh taraf ke-i dari faktor $A$ dan taraf ke-j dari faktor $B$.

$\mu=$ Nilai rata-rata yang sesungguhnya

$K_{k}=$ Pengaruh aditif dari kelompok ke-k

$\alpha_{i}=$ Pengaruh aditif dari taraf ke-i faktor $A$

$\beta_{j}=$ Pengaruh aditif dari taraf ke-j faktor $B$

$\delta_{i k}=$ Pengaruh galat yang muncul pada taraf ke-i dari faktor $A$ dalam kelompok ke-k dan biasa

disebut galat petak utama (galat a)

$(\alpha \beta)_{i j}=$ Pengaruh interaksi taraf ke-i faktor A dan taraf ke-j faktor $B$

$X_{i j k}=$ Observasi ke-ijk pada variabel konkomitan

$\left(X_{i j k}-\bar{x}_{\ldots}\right)=$ Variabel tambahan yang merefleksikan hubungan $X \operatorname{dan} Y$

$\gamma=$ Koefisien regresi yang menunjukan ketergantungan $Y_{i j k}$ pada $X_{i j k}$

$e_{i j k}=$ Pengaruh galat pada kelompok ke-k yang memperoleh taraf ke-i faktor $A$ dan taraf ke-j faktor $B$ dan biasa disebut sebagai galat anak petak (galat $b$ )

Secara umum, model anakova berkorespondensi dengan anava ditambah dengan $\gamma\left(X_{i j k}-\bar{X}_{\ldots}\right)$ untuk merefleksikan hubungan antara variabel $X$ dan $Y$ (Neter dkk, 1997).

\section{Analisis Kovarians pada Rancangan Petak Terbagi pada RAK}

Langkah - langkah analisis kovarinasi rancangan petak terbagi pada RAK adalah sebagai berikut

\section{Pengujian Asumsi}

Asumsi-asumsi yang harus dipenuhi pada analisis kovarians yaitu sebagai berikut :

1. Variabel konkomitan tidak berkorelasi dengan perlakuan yang di cobakan.

a. Pengujian hipotesisnya sebagai berikut :

$H_{0}$ : Variabel konkomitan $(X)$ tidak berkorelasi dengan perlakuan yang dicobakan

$H_{1}$ : Variabel konkomitan $(X)$ berkorelasi dengan perlakuan yang dicobakan

b. Taraf signifikan : $\alpha=0,05$

c. Statistik uji :

$$
\begin{aligned}
& F(A)=\frac{\text { KTA terkoreksi }}{\text { KT galat }(\text { a)terkoreksi }} \\
& F(B)=\frac{\text { KTB terkoreksi }}{\text { KT galat }(b) \text { terkoreksi }}
\end{aligned}
$$

$$
F(A X B)=\frac{K T A X B \text { terkoreksi }}{K T \text { galat }(b) \text { terkoreksi }}
$$

d. Kriteria keputusan

$H_{0}$ : ditolak jika $F_{\text {hit }}>F_{a(b-1, a(r-1))}$

2. Hubungan antara variabel konkomitan $(X)$ dengan variabel respon $(Y)$ bersifat linier. Asumsi ini dapat ditentukan dengan melihat plot dari $(X)$ dan $(Y)$ dimana jika titik-titik amatan mengikuti arah garis lurus maka menunjukkan kecenderungan hubungan antara kedua variabel tersebut bersifat linear. 


\section{YULIANA DEWI PURI, NASRAH.S, NURTITI.S}

3. Galat berdistribusi normal. Asumsi ini dapat ditentukan dengan menggunakan grafik peluang normal dari galat. Jika titik-titik amatan mengikuti arah garis diagonal maka galat tersebut berdistribusi normal.

$>\quad$ Pendugaan parameter $\hat{\mu}$

Diketahui bahwa :

$\sum_{i}^{a} \alpha_{i}=\sum_{j}^{b} \beta_{j}=\sum_{k}^{r} K_{k}=\sum_{i}^{a}(\alpha \beta)_{i j}=\sum_{j}^{b}(\alpha \beta)_{i j} \sum_{i}^{a} \delta_{i k}=\sum_{k}^{r} \delta_{i k}=0$

$\frac{\partial e_{i j k}}{\partial \hat{\mu}}=0$

$\hat{\mu} \quad=\frac{\sum_{i}^{a} \sum_{j}^{b} \sum_{k}^{r} Y_{i j k}}{a b r}=\frac{Y_{\ldots}}{a b r}=\bar{Y}_{\ldots}$

$>\quad$ Pendugaan parameter $\widehat{K}_{k}$

$\frac{\partial \varepsilon_{i j k}}{\partial K_{k}}=0$

$\widehat{K}_{k}=\frac{\sum_{i}^{a} \sum_{j}^{b} Y_{i j k}}{a b}-\frac{\gamma X_{. . k}+\gamma X_{. . .}}{a b}-\mu$

$\widehat{K}_{k}=\bar{Y}_{. . k}-\bar{Y}_{. .}-\hat{\gamma}\left(\bar{X}_{. . k}-\bar{X}_{. . .}\right)$

$>\quad$ Pendugaan parameter $\hat{\alpha}_{i}$

$\frac{\partial \varepsilon_{i j k}}{\partial \alpha_{i}}=0$

$\hat{\alpha}_{i}=\frac{\sum_{j}^{b} \sum_{k}^{r} Y_{i j k}}{b r}-\frac{\gamma\left(X_{i . .}-X_{. . .}\right)}{b r}-\mu$

$\hat{\alpha}_{i}=\bar{Y}_{i . .}-\bar{Y}_{\ldots}-\hat{\gamma}\left(\bar{X}_{i . .}-\bar{X}_{. .}\right)$

$>\quad$ Pendugaan parameter $\hat{\beta}_{j}$

$\frac{\partial \varepsilon_{i j k}}{\partial \beta_{j}}=0$

$\hat{\beta}_{j}=\frac{\sum_{i}^{a} \sum_{k}^{r} Y_{i j k}}{a r}-\frac{\gamma X_{. j .}+\gamma X_{\ldots}}{a r}-\mu$

$\hat{\beta}_{j}=\bar{Y}_{. j .}-\bar{Y}_{\ldots}-\gamma\left(\bar{X}_{. j .}-\bar{X}_{. .}\right)$

$>\quad$ Pendugaan parameter $\hat{\delta}_{i k}$

$\frac{\partial \varepsilon_{i j k}}{\partial \delta_{i k}}=0$

$\hat{\delta}_{i k}=\frac{\sum_{j}^{b} Y_{i j k}}{b}-\frac{\gamma \sum_{j}^{b} X_{i j k}+\gamma \sum_{j}^{b} \bar{X}_{\ldots}}{b}-\mu-K_{k}-\alpha_{i}$

$\hat{\delta}_{i k}=\bar{Y}_{i . k}-\bar{Y}_{\ldots}-K_{k}-\alpha_{i}-\hat{\gamma}\left(\bar{X}_{i . k}-\bar{X}_{\ldots}\right)$

$>\quad$ Pendugaan parameter $(\widehat{\alpha \beta})_{i j}$

$(\widehat{\alpha \beta})_{i j}=\sum_{k}^{r} Y_{i j k}-\gamma X_{i j .}+\gamma X_{\ldots .}-\mu-\alpha_{i}-\beta_{j}$

$(\widehat{\alpha \beta})_{i j}=\bar{Y}_{i j .}-\bar{Y}_{\ldots}-\alpha_{i}-\beta_{j}-\gamma\left(\bar{X}_{i j .}-\bar{X}_{\ldots}\right)$

$>\quad$ Pendugaan parameter $\hat{\gamma}$

$\hat{\gamma}=\frac{J H K G_{X Y}}{J K G_{X}}$ 
sehingga

$\hat{\varepsilon}_{i j k}=Y_{i j k}-\hat{\mu}-\widehat{K}_{k}-\hat{\alpha}_{i}-\hat{\beta}_{j}-\hat{\delta}_{i k}-(\widehat{\alpha \beta})_{i j}-\left(X_{i j k}-\bar{X}_{\ldots}\right)$

Penerapan analisis kovariansi pada Rancangan Petak Terbagi dengan Data Hilang

Penerapan rancangan petak terbagi pada RAK di gambarkan pada percobaan lapangan untuk menilai empat pengelolaan pemupukan nitrogen pada tiga varietas padi. Dimana varietas sebagai petak - utama dan pengelolaan pemupukan sebagai anak petak. Peubah $Y$ adalah banyaknya bulir hampa per malai dan peubah $X$ adalah skor kerusakan akibat wereng coklat pada tanaman padi.

\section{Kesimpulan}

Berdasarakan uraian pada bab sebelumnya mengenai analisis kovariansi rancangan petak terbagi pada RAK maka dapat disimpulkan sebagai berikut:

1. Dari hasil pengujian analisis kovariansi menunjukkan bahwa analisis kovariansi tidak lebih baik dibandingkan analisis variansi pada rancangan petak terbagi hal ini dapat dilihat dari koefisien keragaman dari analisis variansi lebih kecil dari pada analisis kovariansi. Untuk itu direkomendasikan untuk tidak menggunakan analisis kovariansi pada rancangan petak terbagi.

2. Hasil penerapan analisis kovariansi rancangan petak terbagi pada RAK dengan data hilang dilakukan pada percobaan untuk mengetahui pengelolaan pemupukan terhadap varietas tanaman padi. Dari perbandingan koefisien keragaman untuk 119actor A sebesar $49 \%$, koefisien keragaman untuk 119actor B sebesar 32\% pada data lengkap. Dan perbandingan koefisien keragaman untuk 119actor A sebesar $49 \%$, koefisien keragaman untuk 119actor B sebesar 31\% pada data hilang dengan analisis variansi untuk 119actor A sebesar 45\%,119actor B sebesar 31\% pada data lengkap dan analisis variansi untuk 119actor A sebesar 45\%,119actor B sebesar 31\% pada hilang. Hal ini menunjukkan bahwa analisis variansi lebih baik di banding analisis kovariansi.

\section{Saran}

Sebaiknya jangan menggunakan analisis kovariansi rancangan petak terbagi pada RAK dengan data hilang.

\section{DAFTAR PUSTAKA}

[1] Almimi, A., dkk. 2005, Follow-Up Designs to Resolve Confounding in Split-Plot Experiments.Arizona State University, Tempe, AZ 85287.

[2] Auna, Atin. 2010, Analisis Kovarian Dalam Rancangan Bujur Sangkar Latin dengan data hilang. Skripsi tidak diplubikasikan. Universitas Negeri Yogyakarta.

[3] Bradley, J., dkk. 2009, "Split-Plot Designs : What, Why, and How", Journal of Quality Technology, SAS Institute, Cary, NC 27513. 


\section{YULIANA DEWI PURI, NASRAH.S, NURTITI.S}

[4] Erlina. 2010, Analisis Kovarians Pada Rancangan Bujursangkar Hyper Graeco Latin. Universitas Negeri Yogyakarta.

[5] Gaspersz, V., 1991, Metode Perancangan Percobaan. Bandung: CV. Armico.

[6] Kwanchai, G. A., dan Arturo, A. G.,1983, Prosedur Statistika Untuk Penelitian Pertanian.

[7] Neter, J., dan Wasserman,W., 1997, Applied Linier Statistical Model Regression, Analysis of Variance and Eksperimental Design. Illionis : Richard D.R.Win.

[8] Ratna,S., 1997, Analisis Variansi Percobaan Petak Terbagi.Makassar : Universitas Hasanuddin.

[9] Steel, R.G.D., dan Torrie, J.H., 1993. Prinsip dan Prosedur Statistika Suatu Pendekatan Biogeometrik. Jakarta : PT. Gramedia Pustaka Utama

[10] Sudjana.2002, Desain dan Analisis Eksperimen Edisi Ketiga. Bandung : Tarsito.

[11] Walpole, E., 1995, Pengantar Statistika Edisi Ketiga Terjemahan. Jakarta : PT. Gramedia.

[12] William,C.,S., 1987, Statistika Untuk Biologi, Farmasi, Kedokteran, dan Ilmu Yang Bertautan. Bandung: Institut Teknologi Bandung. 